HEALTH ECONOMICS

Health Econ. (2009)

Published online in Wiley InterScience (www.interscience.wiley.com). DOI: 10.1002/hec.1541

\title{
THE IMPACT OF INCOME ON THE WEIGHT OF ELDERLY AMERICANS
}

\author{
JOHN CAWLEY ${ }^{\mathrm{a}, *}$, JOHN MORAN ${ }^{\mathrm{b}}$ and KOSALI SIMON ${ }^{\mathrm{a}}$ \\ ${ }^{a}$ Department of Policy Analysis and Management, Cornell University, Ithaca, NY, USA \\ ${ }^{\mathrm{b}}$ Department of Health Policy and Administration, Pennsylvania State University, University Park, PA, USA
}

\section{SUMMARY}

This paper estimates the impact of income on the body weight and clinical weight classification of elderly Americans using a natural experiment that led otherwise identical retirees to receive significantly different Social Security payments based on their year of birth. We estimate models of instrumental variables using data from the National Health Interview Surveys and find no significant effect of income on weight. The confidence intervals rule out even moderate effects of income on weight and on the probability of being underweight or obese, especially for men. For example, they indicate that the income elasticity of body mass index is not greater in absolute value than 0.06 for men or 0.14 for women. Copyright (C) 2009 John Wiley \& Sons, Ltd.

Received 6 June 2008; Revised 13 May 2009; Accepted 19 June 2009

JEL classification: I 1; I 38; H 55; J 14; J 26

KEY WORDS: obesity; income; instrumental variables

\section{INTRODUCTION}

This paper estimates the causal impact of income on weight and clinical weight classification (e.g. underweight, overweight, and obese). ${ }^{1}$ There are many government programs that provide income to certain groups (e.g. Social Security for the elderly, Temporary Assistance for Needy Families for lowincome women with children), and it would be useful to know whether such programs have an unintended effect on recipient weight. Any such effects could alter the magnitude of the negative externalities due to obesity that operate through public and private health insurance (Bhattacharya and Sood, 2007; Finkelstein et al., 2003). Moreover, knowing the effect of income on weight would provide evidence on the accuracy of the World Health Organization's claim that the recent increase in obesity worldwide is partly due to rising incomes (W.H.O., 2003; Swinburn et al., 2002).

Income could either increase or decrease weight. Income could lead to weight gain if food and sedentary pursuits are normal goods. However, good health and appearance could also be normal goods, leading one to invest more time and money in slimness as income rises. There is some evidence that stress contributes to obesity by increasing caloric intake ('comfort foods') and by decreasing

\footnotetext{
*Correspondence to: Department of Policy Analysis and Management, Cornell University, 124 MVR Hall, Ithaca, NY 14853, USA. E-mail: JHC38@cornell.edu

${ }^{1}$ Weight classifications are based on body mass index (BMI), which is equal to weight in kilograms divided by height in meters squared. Underweight is defined as BMI less than or equal to 18.5 , healthy weight is a BMI between 18.5 and 25 , overweight is defined as a BMI of at least 25 but less than 30, and obese is defined as a BMI of 30 or higher (NIH, 1998).
} 
physical activity (De Vriendt et al., 2009); to the extent that additional income reduces stress, it may result in lower weight.

Obesity among the elderly is a public health and public policy concern because it has consistently been associated with increased risk of disability, limitations in activities of daily living, diabetes, other chronic conditions, and lower quality of life (Lakdawalla et al., 2005b; Heiat et al., 2001; Elia, 2001; Himes, 2000). From age 70 onward, Medicare spends $35 \%$ more on obese individuals than on healthy weight individuals; this amounts to an additional $\$ 39000$ in Medicare costs over a 70-year-old obese person's remaining 14.0 years of life (Lakdawalla et al., 2005b). Finkelstein et al. (2003) estimate that between $\$ 51.5$ and $\$ 78.5$ billion (in 2002 dollars) of Medicare spending per year is attributable to overweight and obesity. These costs are of great concern because elderly obesity has risen dramatically in recent decades. Between 1960-1962 and 1999-2000, the prevalence of obesity rose from 8.4 to $35.8 \%$ among American men aged 60-74, and rose from 26.2 to 39.6\% among American women aged 60-74 (Flegal et al., 2002).

At the lower end of the weight classification system, underweight status is associated with increased risk of morbidity and mortality for the elderly (e.g. Corrada et al., 2006). This correlation motivates us to also examine the impact of Social Security income on underweight status.

To our knowledge, only one published paper has estimated the causal impact of income on weight. ${ }^{2}$ Schmeiser (2008) exploits variation across states in the generosity of the Earned Income Tax Credit (EITC) to estimate the impact of EITC income on the BMI of relatively young (roughly 25-43 years old) low-income Americans. In all models, Schmeiser is unable to reject the null hypothesis of no effect of income on weight for men. His results for women indicate that an additional $\$ 1000$ per year is associated with a gain of between 0.14 and 0.31 BMI units or an average increase of between 0.84 and 1.80 pounds.

This paper and Schmeiser (2008) complement each other, as both estimate the impact of income on weight for vulnerable populations; Schmeiser studies the low income and we study the elderly. Our method involves exploiting a natural experiment in the United States known as the Social Security Benefits Notch, which generated large exogenous differences in income across otherwise identical individuals. Our instrumental variables (IV) estimates yield little evidence that income affects weight or the probability of being underweight or obese among elderly Americans; even moderate-sized effects can be ruled out.

This paper also relates to a substantial recent literature that explores the economic determinants of body weight and obesity; our focus on the effect of income on weight complements the previous literature's contributions regarding the impact on weight of falling food prices (Lakdawalla and Philipson, 2002), increasing maternal employment (Anderson et al., 2003), technological change (Lakdawalla et al., 2005a; Cutler et al., 2003; Lakdawalla and Philipson, 2002; Philipson and Posner, 1999), and reduced smoking (Gruber and Frakes, 2006; Chou et al., 2004).

In subsequent sections, we present our conceptual framework, discuss the natural experiment we exploit (the Social Security Benefits Notch), and describe our data (the National Health Interview Surveys) and empirical methods, before turning to a discussion of the empirical results.

\section{CONCEPTUAL FRAMEWORK}

The conceptual framework for this paper is based on the economic models of body weight in Philipson and Posner (1999), Lakdawalla and Philipson (2002), Cawley (2004b), and Lakdawalla et al. (2005a). In these models, utility is a function of food consumption, the allocation of time to various pursuits, body

\footnotetext{
${ }^{2}$ In contrast, several papers have estimated the causal impact of weight on wages or earnings; e.g. Cawley (2004a), Morris (2006), Lundborg et al. (2007), Brunello and D'Hombres (2007), Norton and Han (2008), and Greve (2008).
} 
weight, health, and a composite good (all other goods). One cannot directly choose body weight or health; they can be affected only through food consumption (caloric intake) and the allocation of time (which determines caloric expenditure). Individuals are assumed to maximize their utility subject to constraints on their time, budget, and biology.

The overall effect of income on weight depends on how income affects food consumption and the allocation of time. Certain categories of food and certain activities may be normal while others may be inferior. A food could have a negative income elasticity of demand (and therefore be inferior) because of its qualities (a classic example is someone decreasing consumption of margarine and increasing consumption of butter after an increase in income), or because health and slimness are normal goods so as income rises people consume less energy-dense foods in order to lose weight (Philipson and Posner, 1999; Philipson, 2001). This reflects the fact that, to some extent, the demand for food and activities is derived from the demand for health and appearance. Philipson and Posner (1999) hypothesize that in developed countries additional income will result in weight loss because of an increased demand for health (which in developed countries far more often entails losing rather than gaining weight) and slim appearance. Ultimately, the impact of income on weight and obesity is an empirical question, and one that we answer in this paper.

Philipson and Posner (1999) and Lakdawalla and Philipson (2002) hypothesize that income has different effects on weight based on initial weight; specifically, that the underweight will gain weight and the overweight and obese will lose weight. This implies that additional income will increase the probability of being healthy weight and decrease the probability of being underweight or overweight. We are unable to explicitly test this hypothesis because our data do not include initial weight (i.e. weight prior to the receipt of additional income); the best that we can do is estimate the impact of income on the probability of being healthy weight. If income raises weight among the underweight and reduces weight among the overweight it should increase the probability of being healthy weight.

Lakdawalla and Philipson (2002) hypothesize that weight may be affected differently by earned income than by unearned income (also see Lakdawalla et al., 2005a). Intuitively, unearned income has a pure income effect, whereas earned income has both an income effect and an effect associated with labor or effort. In this paper, we measure the effect of additional unearned income; an exogenous increase in Social Security benefits. The natural experiment that we use for identification is detailed in the next section.

\section{NATURAL EXPERIMENT: THE SOCIAL SECURITY BENEFITS NOTCH}

Prior to 1972, neither lifetime earnings (upon which Social Security benefits are based) nor postretirement benefit payments were indexed for inflation. Instead, Congress periodically adjusted benefits. In 1972, Congress amended the Social Security Act to provide automatic indexation of credited earnings for workers who had not yet retired. The 1972 Amendments also created an unintentional windfall for workers from certain birth cohorts because of an error that led the prior earnings of these workers to be doubly indexed for inflation. The high rates of inflation that occurred shortly thereafter ensured that this error resulted in a rapid increase in benefits for the affected cohorts. In 1977, Congress eliminated double indexation for future cohorts of retirees by correcting the error in the benefits formula. However, cohorts born prior to 1917 retained doubly indexed (i.e. higher) benefits under a grandfather provision. As a result, a permanent and substantial difference in Social Security payments arose across birth cohorts, which came to be known as the Social Security Benefits Notch (see Figure 1). This difference in benefits was large, unanticipated, ${ }^{3}$ and beyond the control of any individual retiree, and, as a result,

\footnotetext{
${ }^{3}$ The windfall was unanticipated because the benefit difference became apparent only when the various cohorts began receiving Social Security checks (Commission on the Social Security 'Notch' Issue, 1994).
} 


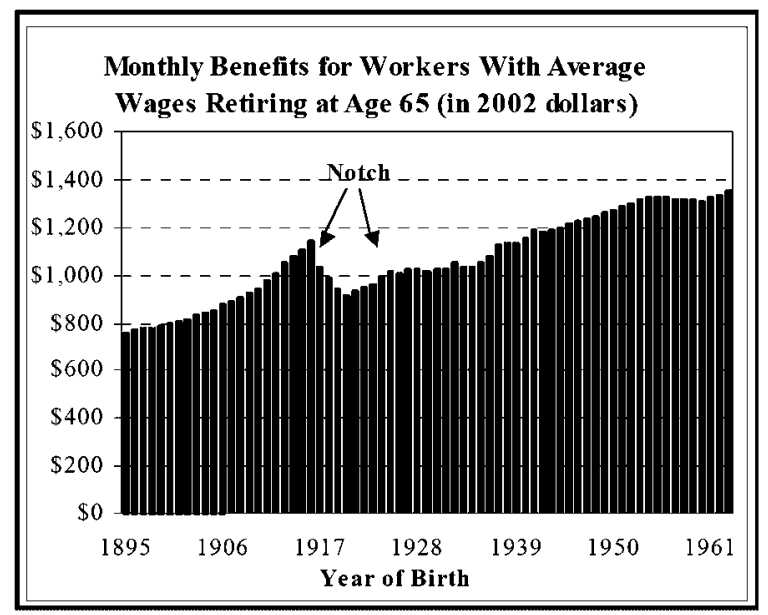

Figure 1. The Social Security Benefits Notch. Note: Reprinted from Kollman (2003)

constitutes a valid natural experiment for estimating income effects among the elderly. The Benefits Notch has been used by others to estimate the effect of income on retirement behavior (Krueger and Pischke, 1992), living arrangements (Engelhardt et al., 2005), mortality (Snyder and Evans, 2006), the demand for prescription drugs (Moran and Simon, 2006), and homeownership (Engelhardt, 2008).

From a research perspective, a fortuitous feature of the Benefits Notch is the permanent nature of the income differentials created by double indexation, which persists throughout retirement for the cohorts that we study. As a result, our estimates will reflect the cumulative impact of all previous additional Social Security income received due to the Notch, as well as any impact due to expectation of future income. Because our outcome of interest is the stock of past consumption (weight), the permanence of the double-indexation windfall is useful because it allows us to estimate the change in steady-state weight due to a longstanding change in income. An isolated single-year windfall might be unlikely to have any contemporaneous impact on the stock of weight, but it is conceivable that a permanent stream of additional income could affect weight. Because we use income data from the early to mid-1990s, and our treatment group consists of households with a primary Social Security beneficiary born between 1915 and 1917, the typical household in our treatment group has been receiving elevated Social Security benefits for slightly more than a decade at the time we observe them.

\section{DATA: NATIONAL HEALTH INTERVIEW SURVEY (NHIS)}

The National Health Interview Survey (NHIS) is a nationally representative survey of the civilian noninstitutionalized population of the United States. The survey interviews approximately 43000 households consisting of approximately 106000 individuals every year. In every year after 1975, selfreported weight and height are recorded. The dollar amount of Social Security benefits was asked from 1990 to 1996. However, Social Security income data for 1993 have never been released for public use. Our data set includes NHIS data from 1990-1992 to 1994-1996. We limit our sample to respondents aged 55 or older in a household headed by a Social Security beneficiary born between 1901 and 1930 . We exclude a small number of households that report no Social Security income or very low amounts (less than \$100/month in 1996 dollars). Across the years 1990-1992 and 1994-1996, our NHIS sample includes 46153 households that are home to roughly 69000 individuals.

Ideally, we would construct our weight variables (BMI and indicator variables for clinical weight classification) using measurements of weight and height. Instead, the NHIS contains self-reports of 
weight and height. Self-reported weight is characterized by reporting error (Rowland, 1989). In general, the direction of reporting bias is negatively correlated with actual weight: underweight people tend to over-report their weight, and overweight people tend to under-report their weight. Such reporting error can result in severe misclassification of individuals into clinical weight categories (Nieto-Garcia et al., 1990). We correct for reporting error in weight and height as in previous research (e.g. Cawley, 2004a,b).

Table I provides descriptive statistics.

\section{METHODS}

Using the exogenous variation in Social Security income attributable to the Benefits Notch, we estimate instrumental variables models to measure the effect of income on body weight. The first- and secondstage equations are shown below:

$$
\begin{gathered}
I_{h t}=\gamma+\theta \operatorname{Notch}_{h}+\phi \mathbf{X}_{i h t}+u_{i h t} \\
\text { Weight }_{i h t}=\alpha+\beta \hat{\mathbf{I}}_{h t}+\delta \mathbf{X}_{i h t}+\varepsilon_{i h t}
\end{gathered}
$$

The subscript $i$ denotes individuals, $h$ households, and $t$ years. In the first stage (Equation (1)), $I_{h t}$ is Social Security income (measured in thousands of 2006 dollars) for household $h$ in year $t$. Income is measured at the household level.

Our instrument, labeled $\operatorname{Notch}_{h}$ in Equation (1), is an indicator variable that equals one for households whose primary Social Security beneficiary was born during the years of 1915-1917 (this is the treatment group - those who benefited most from double indexation of Social Security benefits), and zero for households whose primary Social Security beneficiary was born in any other year between 1901 and 1930 (the control group). There is some discretion in how one defines the group of birth cohorts 'treated' by the Social Security Benefits Notch. We define it as households with a primary Social Security beneficiary born between 1915 and 1917, inclusive, because these are the households that benefited the most from double indexation, and, as a result, provide the greatest variation in Social Security income relative to adjacent cohorts in our NHIS sample. We follow the previous studies that have used the Notch as a natural experiment (Krueger and Pischke, 1992; Engelhardt et al., 2005; Moran and Simon, 2006) in our choice of birth cohorts to include in the control group (1901-1914 and 1918-1930).

As the majority of married women in these birth cohorts qualified for benefits based on their husband's earnings history (Iams and Ycas, 1988; Reno and Ycas, 1982; Snyder and Evans, 2006), we follow Engelhardt et al. (2005) in designating the male member of two-person households as the primary Social Security beneficiary; thus, for all households containing a male, we use the male's year of birth to assign the household to either the treatment or the control group. Households with no males can be divided into two categories: never-married females and widowed/divorced females. In the case of nevermarried females, we designate the female as the primary beneficiary and use her year of birth to determine treatment-control status for the household. In the case of widowed or divorced females, we designate the deceased or former husband as the primary beneficiary and subtract 3 years from the female's year of birth to impute a birth year for the deceased or former husband. ${ }^{4}$ As a robustness check, we also re-estimate our baseline models excluding divorced and widowed females.

In Equations (1) and (2), $\mathbf{X}_{\text {iht }}$ is a vector of control variables at the individual or household level, specifically: race (white, black), Hispanic ethnicity, education (less than high school, high school graduate, some college, college graduate, more than college), marital status (married household, single

${ }^{4}$ Engelhardt, Gruber and Perry (2005) note that 3 years is the median difference in spousal ages for widowed or divorced elderly. 


\section{J. CAWLEY ET AL.}

Table I. Descriptive statistics of selected variables, mean and (standard deviation)

\begin{tabular}{|c|c|c|}
\hline Variable & $\begin{array}{c}\text { Males } \\
(N=28503)\end{array}$ & $\begin{array}{c}\text { Females } \\
(N=42011)\end{array}$ \\
\hline Household Social Security income, in 2006 dollars & $\begin{array}{l}16023.98 \\
(6580.14)\end{array}$ & $\begin{array}{l}13896.53 \\
(6445.19)\end{array}$ \\
\hline Indicator for treatment & 0.12 & 0.13 \\
\hline (i.e. primary Social Security beneficiary was born 1915-1917) & $(0.32)$ & $(0.34)$ \\
\hline Body mass index (BMI), corrected for reporting error & $\begin{array}{l}26.19 \\
(4.04)\end{array}$ & $\begin{array}{l}26.39 \\
(5.43)\end{array}$ \\
\hline Underweight & $\begin{array}{c}0.02 \\
(0.13)\end{array}$ & $\begin{array}{c}0.04 \\
(0.20)\end{array}$ \\
\hline Healthy weight & $\begin{array}{c}0.39 \\
(0.49)\end{array}$ & $\begin{array}{c}0.40 \\
(0.49)\end{array}$ \\
\hline Overweight & $\begin{array}{c}0.44 \\
(0.50)\end{array}$ & $\begin{array}{c}0.34 \\
(0.47)\end{array}$ \\
\hline Obese & $\begin{array}{c}0.15 \\
(0.36)\end{array}$ & $\begin{array}{c}0.22 \\
(0.42)\end{array}$ \\
\hline Years between 1989 and survey year & $\begin{array}{c}3.96 \\
(2.15)\end{array}$ & $\begin{array}{l}4.00 \\
(2.16)\end{array}$ \\
\hline Resident of region 1 & $\begin{array}{c}0.22 \\
(0.41)\end{array}$ & $\begin{array}{c}0.22 \\
(0.42)\end{array}$ \\
\hline Resident of region 2 & $\begin{array}{c}0.26 \\
(0.44)\end{array}$ & $\begin{array}{c}0.26 \\
(0.44)\end{array}$ \\
\hline Resident of region 3 & $\begin{array}{c}0.34 \\
(0.47)\end{array}$ & $\begin{array}{c}0.35 \\
(0.48)\end{array}$ \\
\hline Resident of region 4 & $\begin{array}{c}0.18 \\
(0.39)\end{array}$ & $\begin{array}{c}0.17 \\
(0.38)\end{array}$ \\
\hline Lives in a metropolitan area & $\begin{array}{c}0.61 \\
(0.49)\end{array}$ & $\begin{array}{c}0.61 \\
(0.49)\end{array}$ \\
\hline Age of the primary Social Security beneficiary & $\begin{array}{l}72.72 \\
(6.34)\end{array}$ & $\begin{array}{l}74.88 \\
(6.98)\end{array}$ \\
\hline Primary Social Security beneficiary is Hispanic & $\begin{array}{c}0.03 \\
(0.18)\end{array}$ & $\begin{array}{c}0.03 \\
(0.17)\end{array}$ \\
\hline Primary Social Security beneficiary is White & $\begin{array}{c}0.92 \\
(0.27)\end{array}$ & $\begin{array}{c}0.92 \\
(0.28)\end{array}$ \\
\hline Primary Social Security beneficiary is Black & $\begin{array}{c}0.07 \\
(0.26)\end{array}$ & $\begin{array}{c}0.08 \\
(0.27)\end{array}$ \\
\hline Primary Social Security beneficiary education is less than HS & $\begin{array}{c}0.39 \\
(0.49)\end{array}$ & $\begin{array}{c}0.39 \\
(0.49)\end{array}$ \\
\hline Primary Social Security beneficiary education is HS & $\begin{array}{c}0.32 \\
(0.46)\end{array}$ & $\begin{array}{c}0.34 \\
(0.48)\end{array}$ \\
\hline Primary Social Security beneficiary education is some college & $\begin{array}{c}0.13 \\
(0.33)\end{array}$ & $\begin{array}{c}0.13 \\
(0.34)\end{array}$ \\
\hline Primary Social Security beneficiary education is college & $\begin{array}{c}0.09 \\
(0.28)\end{array}$ & $\begin{array}{c}0.07 \\
(0.26)\end{array}$ \\
\hline Primary Social Security beneficiary education is more than college & $\begin{array}{c}0.08 \\
(0.27)\end{array}$ & $\begin{array}{c}0.06 \\
(0.24)\end{array}$ \\
\hline Household is headed by a single male & $\begin{array}{c}0.21 \\
(0.41)\end{array}$ & $\mathrm{n} / \mathrm{a}$ \\
\hline Household is headed by a never-married female & $\mathrm{n} / \mathrm{a}$ & $\begin{array}{c}0.03 \\
(0.17)\end{array}$ \\
\hline Household is headed by female widow & $\mathrm{n} / \mathrm{a}$ & $\begin{array}{c}0.39 \\
(0.49)\end{array}$ \\
\hline Household is headed by female divorcee & $\mathrm{n} / \mathrm{a}$ & $\begin{array}{c}0.05 \\
(0.22)\end{array}$ \\
\hline Primary Social Security beneficiary's birth year & $\begin{array}{c}1919.75 \\
(6.48)\end{array}$ & $\begin{array}{c}1917.64 \\
(7.09)\end{array}$ \\
\hline
\end{tabular}

Notes: Weighted data on respondents to NHIS 1990-1992 and 1994-1996 born 1901-1930. 'Primary Social Security beneficiary' refers to the person in the household whose birth year determines whether the person in question is affected by the Notch. For example, in the case of a woman living with her married male partner, it is his birth year that counts. 
male, divorced female, widowed female, never-married female), urban residence, region of residence, year (as linear and quadratic), and a full set of indicator variables for age. For married, widowed, and divorced women, we also control for the age of the primary Social Security recipient in the household in linear and quadratic terms.

In the second stage (Equation (2)), Weight ${ }_{i h t}$ is initially measured by BMI. However, Philipson and Posner (1999) and Lakdawalla and Philipson (2002) hypothesize that additional income will increase the probability of being healthy weight and decrease the probability of being underweight, overweight, or obese. We test these hypotheses by using indicator variables for clinical weight classification

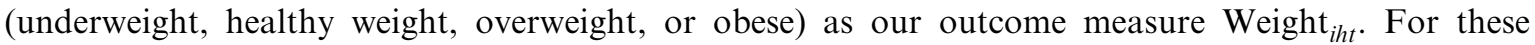
binary dependent variables we estimate Equation (2) using two-stage least squares (2SLS) because IV probit models failed to converge in most cases. ${ }^{5}$ (The IV probit marginal effects that could be estimated were similar to the 2SLS coefficients, and in each case the associated confidence interval (C.I.) was tighter; thus, it seems likely that we would have been able to further narrow the range of excluded effect sizes had IV probit estimation proved feasible.)

The variable $\hat{\mathbf{I}}_{h t}$ is predicted Social Security income from the first-stage regression (Equation (1)). Our identifying assumption is that after controlling for age fixed effects, the variation in Social Security income induced by the Notch is uncorrelated with the unobserved determinants of body weight, as reflected in the error term. Conditional on this assumption, the second-stage coefficient on predicted Social Security income, $\beta$, will measure the causal impact of income on body weight.

When estimating Equations (1) and (2), data are weighted using NHIS survey weights, and standard errors are clustered by year of birth.

\section{EMPIRICAL RESULTS}

We first describe the basic correlation between body weight and Social Security income in the NHIS among those born 1901-1930. Table II summarizes, for increments of $\$ 5000$ in Social Security income (in 2006 dollars), the average BMI and percent obese for women and men. The prevalence of obesity tends to fall with income for women, from $24.6 \%$ among those with $\$ 5000$ or less in annual Social Security income to $20.1 \%$ among those with $\$ 20000$ to $\$ 25000$ annual benefits, a difference of $4.5 \%$ points. In contrast, among men the prevalence of obesity rises and then remains roughly constant with income; the difference between the prevalence of obesity in the highest and lowest income categories is just $1.2 \%$ points. These patterns are consistent with those previously found for the population as a whole (Sobal and Stunkard, 1989).

We next present the results of regression models that do not instrument for income. The first column of Table III, which presents results for females, indicates that an extra $\$ 1000$ of Social Security income is associated with 0.013 units lower BMI (Table III, column 1). For a woman who is $5 \mathrm{ft}, 2$ in tall, this translates into less than one-tenth of a pound. Among men (Table III, column 3), an extra $\$ 1000$ of Social Security income is associated with 0.013 units higher BMI (which is the same magnitude, but opposite sign, as women). For a man who is $5 \mathrm{ft}, 10 \mathrm{in}$ tall, this translates into less than one-tenth of a pound.

However, the correlation between income and weight may be non-linear, so we present correlations of clinical weight classification with Social Security income. Table III, column 1, indicates that among females an extra $\$ 1000$ of Social Security income is associated with a $0.1 \%$ point lower probability of underweight and a $0.1 \%$ point lower probability of obesity, both of which are statistically significant at

\footnotetext{
${ }^{5} \mathrm{We}$ also attempted to estimate quantile IV models to see if the impact of income on body weight varied at different points in the weight distribution, but these models also failed to converge.
} 


\section{J. CAWLEY ET AL.}

Table II. Average BMI and percent obese by category of Social Security income

\begin{tabular}{|c|c|c|c|c|}
\hline \multirow{2}{*}{$\begin{array}{l}\text { Household Social } \\
\text { Security Income }\end{array}$} & \multicolumn{2}{|c|}{ Females } & \multicolumn{2}{|c|}{ Males } \\
\hline & Average BMI & Percent obese & Average BMI & Percent obese \\
\hline$\$ 0-\$ 5000$ & 26.74 & 24.6 & 25.98 & 14.4 \\
\hline$\$ 5000-\$ 10000$ & 26.75 & 25.2 & 26.04 & 15.7 \\
\hline$\$ 10000-\$ 15000$ & 26.39 & 22.8 & 26.25 & 15.8 \\
\hline$\$ 15000-\$ 20000$ & 26.22 & 20.5 & 26.23 & 15.4 \\
\hline$\$ 20000-\$ 25000$ & 26.16 & 20.1 & 26.33 & 15.6 \\
\hline
\end{tabular}

Data: Respondents to NHIS 1990-1992 and 1994-1996 born 1901-1930. Sample weights are used. Income is in $2006 \$$.

Table III. Income and weight among elderly males and females

\begin{tabular}{|c|c|c|c|c|}
\hline \multirow[b]{2}{*}{ Dependent variable } & \multicolumn{2}{|c|}{ Females $(N=42011)$} & \multicolumn{2}{|c|}{ Males $(N=28503)$} \\
\hline & $\begin{array}{c}\text { OLS or LPM } \\
\text { coefficient on Social } \\
\text { Security income } \\
\text { (in 1000s) }\end{array}$ & $\begin{array}{l}\text { 2SLS coefficient } \\
\text { on Social Security } \\
\text { income (in 1000s) } \\
\text { and } 95 \% \text { C.I. }\end{array}$ & $\begin{array}{l}\text { OLS or LPM } \\
\text { coefficient on Social } \\
\text { Security income } \\
\text { (in 1000s) }\end{array}$ & $\begin{array}{l}\text { 2SLS coefficient on } \\
\text { Social Security } \\
\text { income (in 1000s) } \\
\text { and } 95 \% \text { C.I. }\end{array}$ \\
\hline Body mass index & $\begin{array}{c}-0.013^{* * *} \\
(0.005)\end{array}$ & $\begin{array}{c}0.010 \\
(0.122) \\
{[-0.229,0.249]}\end{array}$ & $\begin{array}{l}0.013^{* * *} \\
(0.003)\end{array}$ & $\begin{array}{c}-0.007 \\
(0.045) \\
{[-0.095,0.081]}\end{array}$ \\
\hline Indicator for underweight & $\begin{array}{c}-0.001^{* *} \\
(0.0002)\end{array}$ & $\begin{array}{c}0.004 \\
(0.005) \\
{[-0.006,0.014]}\end{array}$ & $\begin{array}{c}-0.001^{* * *} \\
(0.0001)\end{array}$ & $\begin{array}{c}-0.001 \\
(0.001) \\
{[-0.003,0.001]}\end{array}$ \\
\hline Indicator for healthy weight & $\begin{array}{c}0.002^{* * * *} \\
(0.0005)\end{array}$ & $\begin{array}{c}-0.011 \\
(0.018) \\
{[-0.046,0.024]}\end{array}$ & $\begin{array}{l}-0.001 \\
(0.001)\end{array}$ & $\begin{array}{c}0.004 \\
(0.005) \\
{[-0.006,0.014]}\end{array}$ \\
\hline Indicator for overweight & $\begin{array}{c}0.0002 \\
(0.0004)\end{array}$ & $\begin{array}{c}0.016 \\
(0.013) \\
{[-0.01,0.042]}\end{array}$ & $\begin{array}{l}0.0007 \\
(0.006)\end{array}$ & $\begin{array}{c}-0.006 \\
(0.005) \\
{[-0.016,0.004]}\end{array}$ \\
\hline Indicator for obese & $\begin{array}{c}-0.001^{* * *} \\
(0.0004)\end{array}$ & $\begin{array}{c}-0.010 \\
(0.011) \\
{[-0.032,0.012]}\end{array}$ & $\begin{array}{c}0.0004 \\
(0.0004)\end{array}$ & $\begin{array}{c}0.002 \\
(0.003) \\
{[-0.004,0.008]}\end{array}$ \\
\hline $\begin{array}{l}\text { First-stage Notch } \\
\text { coefficient (in 1000s) }\end{array}$ & - & $\begin{array}{l}1.128^{* * *} \\
(0.210)\end{array}$ & & $\begin{array}{l}0.703^{* * *} \\
(0.143)\end{array}$ \\
\hline $\begin{array}{l}\text { Partial } F \text {-statistic } \\
\text { Partial } R \text {-squared }\end{array}$ & - & $\begin{array}{c}24.21 \\
0.12\end{array}$ & - & $\begin{array}{l}28.76 \\
0.23\end{array}$ \\
\hline
\end{tabular}

Notes: Data come from the National Health Interview Survey, 1990-1992 and 1994-1996. Estimation samples consist of males born 1901-1930 and females in households headed by a Social Security beneficiary born 1901-1930. With the exception of the final three rows, each cell in the table corresponds to a separate regression. Standard errors are in parentheses; 95\% C.I.s are in brackets. ${ }^{*}$ indicates statistical significance at the $10 \%$ level; ${ }^{* *}$ indicates significance at the $5 \%$ level; and ${ }^{* * *}$ indicates significance at the $1 \%$ level. Other covariates include year (as linear and quadratic) and indicator variables for age of respondent, race, Hispanic, education category, marital status, urban residence, and region of residence. In cases where the respondent is not the primary Social Security beneficiary, we also control for the age of the primary Social Security beneficiary in the household (as linear and quadratic).

the $10 \%$ level or better. Conditional on our regressors, women with $\$ 1000$ higher Social Security incomes are $0.2 \%$ points more likely to be healthy weight.

Among males (Table III, column 3), an extra $\$ 1000$ of Social Security income is associated with a $0.1 \%$ point lower probability of underweight but no statistically significant difference in the probability of being healthy weight, overweight, or obese.

These correlations are hard to interpret, because they potentially reflect many distinct effects: the effect of income on weight, the impact of weight on lifetime earnings (and subsequently, Social Security 


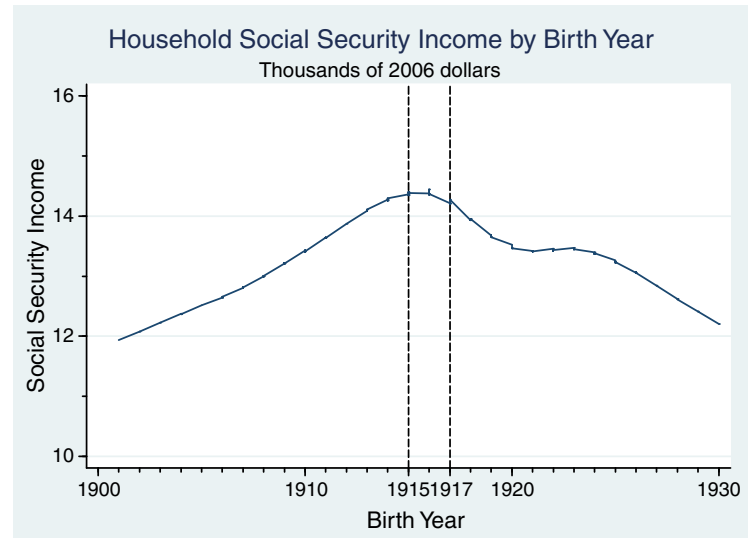

Figure 2. Annual Social Security income by birth year. Notes: Data: NHIS 1990-1992 and 1994-1996. Income is conditioned on all basic regressors (i.e. except birth year and age fixed effects) in our model to produce a smoothed series. In this paper, cohorts born 1915-1917 (i.e. those between the vertical dashed lines), who received peak benefits, serve as the treatment group and those born 1901-1914 and 1918-1930, who received lesser benefits, serve as the control group. Income is in 2006 dollars

benefits), and unobserved characteristics that may affect both weight and earnings (and subsequently, Social Security benefits).

Before presenting IV results, we first check whether the Social Security Notch generated significant differences in Social Security income across birth cohorts in the NHIS. Using data from the NHIS from 1990-1992 to 1994-1996, we graph household Social Security income by birth year for all birth cohorts between 1901 and 1930 after conditioning on other explanatory variables. Figure 2 illustrates that NHIS respondents born 1915-1917 (highlighted on the graph as the birth cohorts between the vertical dashed lines) enjoy higher annual Social Security benefits than those born in other years between 1901 and 1930. Compared with the control group, the treatment group receives Social Security benefits that are, on average, $7 \%$ higher for men and $5 \%$ higher for women. In terms of annual Social Security income, treatment group men receive $\$ 1122$ more and treatment group women receive $\$ 695$ more each year, and these higher benefits are received every year for the rest of the recipient's life.

Annual income increases of this magnitude have the potential to affect body weight because even small changes in daily caloric intake can result in large changes in body weight over time. For example, Hill et al. (2003) estimate that the recent increase in weight in the US was caused by a daily calorie surplus of just 15 calories for the median person. ${ }^{6}$ Apovian (2004) finds that consuming an additional 12-ounce can of non-diet soda per day will add 15 pounds to a person's weight in 1 year. For this reason, even if the extra $\$ 1130$ annual Social Security income affected daily caloric intake only slightly, it has the potential to cause large changes in body weight.

Test statistics indicate that the Notch is a suitably powerful instrument for income. The partial $F$-statistics from our first-stage regressions are 24.21 for women and 28.76 for men, more than twice the minimum standard of 10 (Stock et al., 2002). The identifying assumption behind our IV estimation strategy is that being born between 1915 and 1917 affected Social Security income, but did not directly affect body weight, conditional on the observables in our second-stage regression. We have already confirmed the first part of that assumption. The second part of the identifying assumption, that the instrument (Notch status) is uncorrelated with the second-stage error term is, strictly speaking, untestable. However, we can look for suggestive evidence on this by examining whether the weight of

\footnotetext{
${ }^{6}$ How a given change in daily caloric intake translates into a change in weight likely varies with age. We have been unable to find estimates specific to the elderly and hence we use the Hill et al. estimates as the best available.
} 
the treatment group varied from that of the control group prior to receipt of any Social Security income. If we find that the treatment group looked different from our control group with respect to our outcome of interest (BMI), that would cast doubt on our identifying assumption (Heckman and Hotz, 1989).

Figure 3 plots average BMI, conditional on our second-stage regressors, by birth year for women (men) in the National Health Interview Survey of 1976. Only those who have not yet retired are included in the sample, allowing us to compare the treatment and control groups before the treatment occurs. For both women and men, the average BMI of the treatment group cohorts (shown between the vertical dashed lines) closely resembles that of the adjacent birth-year cohorts in the control group. For women (the lower line), average BMI is quite flat, whereas for men (the upper line) there are small variations over birth-year cohorts, but in neither graph is the average BMI of the treatment group noticeably different from that of the control group. Estimates from reduced form regressions confirm that there are no statistically significant differences in pre-retirement BMI for the Notch cohort. Although this evidence is suggestive rather than definitive, it is consistent with our identifying assumption that birth year had no effect on BMI other than through Social Security income, conditional on our observables.

Figure 4 shows reduced form graphs of the IV results for the 1990s data: it depicts average BMI by birth year, conditional on our second-stage regressors. The data depicted in Figure 4 provide little evidence of an effect of income on BMI; for both females and males, the average BMI of the treatment group is very similar to that of adjacent birth cohorts in the control group.

The results of our IV regressions are summarized in Table III, columns 2 (females) and 4 (males). For both males and females, the IV coefficient on Social Security income is statistically indistinguishable from zero for each dependent variable (BMI, underweight, overweight, healthy weight, and obesity) in all of our regressions. As is often the case, the IV standard errors are larger in absolute magnitude than those from models in which the endogenous variable has not been instrumented.

The most useful way to interpret our results may be to consider the effect sizes they allow us to rule out. Columns 2 and 4 of Table III present 95\% C.I.s for our IV estimates (defined as within 1.96 standard errors of the IV point estimate). In each case, the $95 \%$ C.I. includes both zero and OLS estimate. Moreover, these C.I.s generally exclude even moderate-sized effects of income on weight,

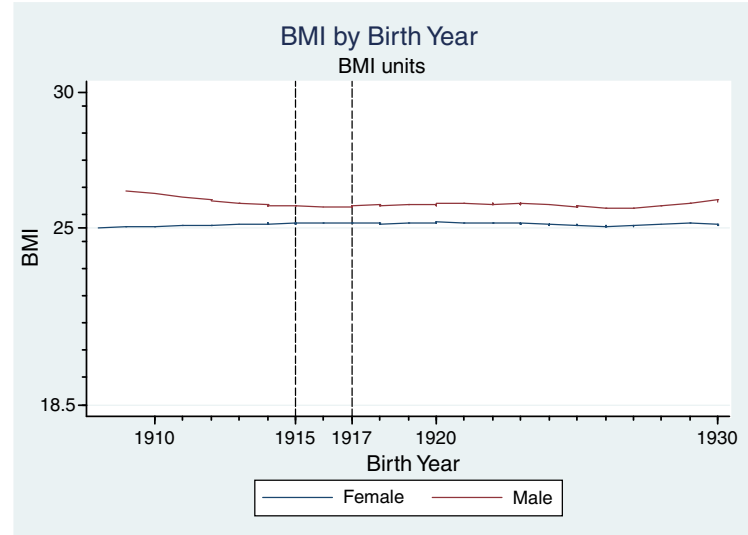

Figure 3. Pre-retirement BMI by birth year, females (lower line), and males (upper line). Notes: Data: NHIS 1976. Non-retired individuals under the age of 65 are used in this calculation. BMI is conditioned on all basic regressors (i.e. except birth year and age fixed effects) in our model to produce a smoothed series. In this paper, cohorts born 1915-1917 (i.e. those between the vertical dashed lines), who received peak benefits, serve as the treatment group and those born 1901-1914 and 1918-1930, who received lesser benefits, serve as the control group. Females are the lower line and males are the upper line 


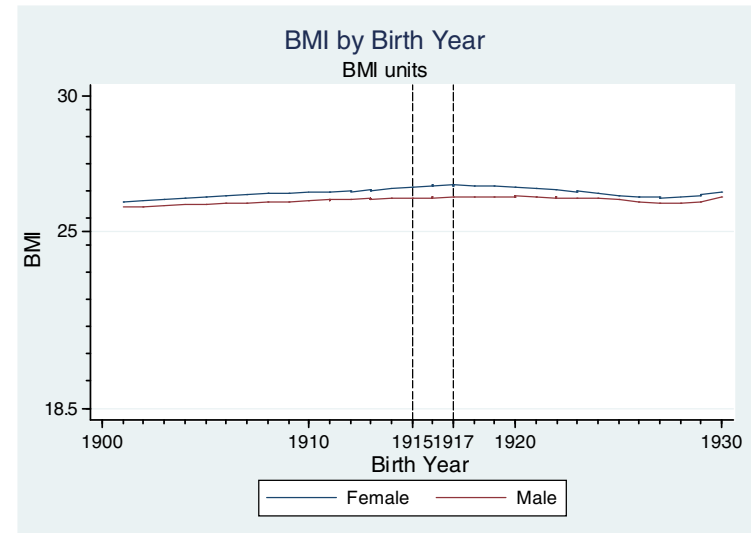

Figure 4. Post-retirement BMI by birth year. Notes: Data: NHIS 1990-1992 and 1994-1996. BMI is conditioned on all basic regressors (i.e. except birth year and age fixed effects) in our model to produce a smoothed series. In this paper, cohorts born 1915-1917 (i.e. those between the vertical dashed lines), who received peak benefits, serve as the treatment group and those born 1901-1914 and 1918-1930, who received lesser benefits, serve as the control group.

Females are the upper line and males are the lower line

especially for men. In considering the effect sizes that can be excluded, one should keep in mind that they correspond to a permanent $\$ 1000$ increase in annual Social Security income (in 2006 dollars), which is, on average, an increase of $7.2 \%$ for the females, and $6.2 \%$ for the males, in our sample.

Among men (Table III, column 4), our estimated C.I.s allow us to reject the hypothesis that a permanent increase of $\$ 1000$ in annual Social Security income lowers BMI by more than 0.095 units, or raises BMI by more than 0.081 units. This implies that, for a man who is $5 \mathrm{ft} 10 \mathrm{in}$ tall, the extra income will not lower or raise weight by even two-thirds of 1 pound. The C.I. on the IV coefficient implies that the income elasticity of BMI cannot be less than -0.058 or greater than 0.05 for men.

Similarly, our C.I.s suggest that an extra $\$ 1000$ in annual Social Security income does not decrease the risk of underweight by more than one-third of a percentage point or raise the risk of underweight by more than one-tenth of a percentage point among men. We can also rule out reductions in the probability of overweight of more than $1.6 \%$ points, or increases in the probability of overweight of more than $0.4 \%$ points. Similarly, the results rule out a reduction in the probability of obesity of more than $0.4 \%$ points or an increase in the probability of obesity of more than $0.8 \%$ points. Finally, we can reject the hypothesis that an extra $\$ 1000$ in Social Security income raises the probability that a man is healthy weight by more than $1.4 \%$ points or lowers it by more than $0.6 \%$ points.

The ranges of possible effect sizes are greater for women than men, but are still fairly modest in the case of BMI and underweight. Among women (Table III, column 2), an extra $\$ 1000$ in annual Social Security income will not lower BMI by more than 0.229 units or raise BMI by more than 0.249 units; for a woman who is $5 \mathrm{ft} 2 \mathrm{in}$ tall, the extra income will not lower weight by more than 1.25 pounds or raise it by more than 1.36 pounds. The C.I. on the IV coefficient implies that the income elasticity of BMI cannot be less than -0.120 or greater than 0.131 for women.

For women, an extra $\$ 1000$ in Social Security income is unlikely to lower the risk of underweight by more than $0.6 \%$ points or raise the risk of underweight by more than $1.4 \%$ points. For women's risk of overweight and obesity, substantial effects remain within the C.I. Our estimates imply that an extra $\$ 1000$ per year does not lower the risk of overweight by more than $1 \%$ point or raise it by more than $4.2 \%$ points, nor would it decrease the risk of obesity by more than $3.2 \%$ points or raise the risk of obesity by more than $1.2 \%$ points. Finally, our estimates indicate that an extra $\$ 1000$ in annual Social Security income would not raise the probability that a woman is healthy weight by more than $2.4 \%$ points or lower it by more than $4.6 \%$ points. 
Because of the need to impute a birth year to the former husbands of divorced and widowed females, we re-estimated our baseline models excluding these women from the sample and found that results for the remaining women generally allowed us to rule out even smaller effects. ${ }^{7}$ For example, in the case of BMI, we were able to exclude effect sizes of greater than +0.103 and less than -0.154 BMI units for each $\$ 1000$ increase in income, compared with corresponding effect sizes for the full sample of +0.249 and -0.229 , respectively. Similarly, we find that in this subsample an additional $\$ 1000$ of income will not increase the probability of being underweight by more than $1.1 \%$ points (vs $1.4 \%$ points in the full sample), will not increase the probability of being overweight by more than $2.3 \%$ points (vs $4.2 \%$ points in the full sample), and will not lower the probability of being obese by more than $1.9 \%$ points (vs $3.2 \%$ points in the full sample).

\section{LIMITATIONS}

Our analysis has several limitations. First, because our outcome of interest is weight, which is the stock of past consumption, lagged income as well as contemporaneous income is relevant. Unfortunately, the NHIS does not include lifetime income streams. ${ }^{8}$ However, because members of the treatment group have received elevated Social Security payments for as long as they have received Social Security benefits, our estimates of the effect of income on weight reflect not just the contemporaneous effect of a 1 -year increase in income, but also the impact of all prior windfall payments due to the Notch and any impact of knowing that one's future Social Security income will forever include such windfall payments. Thus, our estimates to a certain extent reflect lagged and future income and therefore are overestimates of the impact of contemporaneous income on weight, which makes our inability to reject the null hypothesis of no effect even more interesting and informative.

Second, because our estimates are based on differences in Social Security payments received after retirement, they may not generalize to other sources of income. For example, if work is sedentary, changes in earned income may imply a bigger increase in weight than changes in unearned income if the rise in earned income is accompanied by a reduction in overall physical activity (Lakdawalla and Philipson, 2002; Lakdawalla et al., 2005a).

Because of the failure of our probit IV models to converge, we estimate linear regressions for dichotomous outcomes. As a result, our estimates may be inefficient.

An additional limitation of this study is that BMI does not distinguish fat from lean mass (Prentice and Jebb, 2001; US DHHS, 2001). Regrettably, publicly available data sets with the relevant Social Security data lack more accurate measures of fatness (Smalley et al., 1990; Garn et al., 1986; Burkhauser and Cawley, 2008), and hence we were limited to using BMI for this study.

Another limitation is that the NHIS data lack measures of diet and physical activity, which precludes us from investigating the specific channels through which income may affect weight.

The generalizability of our results may also be restricted to variations in income similar in magnitude to those generated by the Benefits Notch. For the average household in our sample, this corresponds to a difference in benefits of about $5-7 \%$, which is similar in magnitude to the $5 \%$ cut proposed by the 'Boskin Commission' in the mid-1990s (see Snyder and Evans, 2006) and the 10\% reduction that would arise by the year 2015 if a recent proposal to switch from wage indexing to price indexing were enacted (see Biggs et al., 2005). Moreover, given that the income differences induced by the Benefits Notch have been shown to exert a significant influence on other important outcomes, e.g. elderly living arrangements (Engelhardt et al., 2005) and prescription drug use (Moran and Simon, 2006), our ability to rule out even moderately sized effects on body weight are informative.

\footnotetext{
${ }^{7}$ For this sample of women $(N=23295)$, the $F$-statistic on the excluded instruments is equal to 26.14 .

${ }^{8}$ Even if this information were available, we would not have any way of isolating exogenous differences in lifetime earnings.
} 
Finally, the extent to which our results generalize to younger populations is unclear. Given that obesity is a risk factor for mortality in middle age (Stevens et al., 1998), those who survive to receive Social Security are those who in their younger years were disproportionately either healthy weight or unusually healthy despite being overweight or obese. Thus, relative to the population as a whole, our sample of surviving elderly is a select sample, and therefore one should be cautious about generalizing these results to younger ages. Another reason for caution in generalizing to younger populations is that habit formation may play a role in food expenditures and consumption (Heien and Durham, 1991; Naik and Moore, 1996). Elderly people, who have had more time to develop habits, may be especially consistent in their food expenditures (and consumption), implying that the relationship between income and weight may be weaker for the elderly than for the population as a whole.

Still, answering this question for the elderly is an important end in itself because weight status is correlated with morbidity, functioning, and mortality among the elderly, and because the elderly are among the most vulnerable in society, with a third of those aged 65 and over receiving all or almost all of their retirement income from Social Security (Social Security Administration, 2006a,b). ${ }^{9}$ At a minimum, we provide results for that population of interest.

\section{DISCUSSION}

Our IV estimates yield little evidence that income affects weight or the probability of being underweight, healthy weight, overweight, or obese among elderly Americans. The strongest conclusions one can draw from our analysis concern the effect sizes that our IV estimates allow us to rule out. An increase in Social Security income of $\$ 1000$ a year represents an average increase in income of 7.2 and $6.2 \%$ for women and men in our sample. Our IV results indicate that an increase in income of this size, received every year for the rest of one's life, will not increase or decrease weight by even a pound among men, or by 1.5 pounds among women. The medical literature has detected improvements in health for weight loss of 5-10\% among the obese (Arbeeny, 2004; Fujioka, 2002), but there is no published evidence that losing a pound or two will improve health. In other words, any plausible weight loss associated with a $6-7 \%$ change in Social Security income for the rest of one's life is not expected to have any detectable impact on health, at least through weight.

The empirical estimates in this paper have important implications for public policy. First, our estimates suggest that changes in Social Security benefits of the magnitude considered in several recent reform proposals would not have a meaningful effect on weight. Our estimates also imply that altering the level of Social Security benefits is unlikely to be an effective policy lever to alter the external costs of obesity imposed through public health insurance programs. Finally, our estimates provide no support for the World Health Organization's claim that rising income is partly to blame for the recent increase in obesity.

\section{ACKNOWLEDGEMENTS}

For their helpful comments, the authors thank Susan Ettner, Jay Bhattacharya, Shin-Yi Chou, Tomas Philipson, Diane Whitmore Schanzenbach, anonymous referees, and conference participants at the International Health Economics Association World Congress, Allied Social Science Association meetings, the Biennial Conference of the American Society of Health Economists, NBER Summer Institute in Health Economics, and Association for Public Policy Analysis and Management Fall Conference.

\footnotetext{
${ }^{9}$ Almost two-thirds of those aged 65 and over receive at least half of their retirement income from Social Security (Social Security Administration, 2006a,b).
} 


\section{J. CAWLEY ET AL.}

\section{REFERENCES}

Anderson PM, Butcher KF, Levine PB. 2003. Maternal employment and overweight children. Journal of Health Economics 22: 477-504.

Apovian CM. 2004. Sugar-sweetened soft drinks, obesity, and type 2 diabetes. Journal of the American Medical Association 292(8): 978-979.

Arbeeny CM. 2004. Addressing the unmet medical need for safe and effective weight loss therapies. Obesity Research 12(8): 1191-1196.

Bhattacharya J, Sood N. 2007. Health insurance and the obesity externality. In The Economics of Obesity, Advances in Health Economics and Health Services Research, Bolin K, Cawley J (eds), vol. 17. Elsevier: Amsterdam; 279-318.

Biggs A, Brown J, Springstead G. 2005. Alternative methods of price indexing social security: implications for benefits and system financing. NBER Working Paper.

Brunello G, D'Hombres B. 2007. Does body weight affect wages? evidence from Europe. Economics and Human Biology 5: 1-19.

Burkhauser RV, Cawley J. 2008. Beyond BMI: the value of more accurate measures of fatness and obesity in social science research. Journal of Health Economics 27(2): 519-529.

Cawley J. 2004a. The impact of obesity on wages. Journal of Human Resources 39(2): 451-474.

Cawley J. 2004b. An economic framework for understanding physical activity and eating behaviors. American Journal of Preventive Medicine 27(3S): 117-125.

Chou S-Y, Grossman M, Saffer H. 2004. An economic analysis of adult obesity: results from the behavioral risk factor surveillance system. Journal of Health Economics 23(3): 565-587.

Commission on the Social Security 'Notch' Issue. 1994. Final Report on the Social Security 'Notch' Issue. Social Security History Archives, Washington, DC. Available from: http://www.socialsecurity.gov/history/notchbase. html (Last access date September 2006).

Corrada MM, Kawas CH, Mozaffar F et al. 2006. Association of body mass index and weight change with all-cause mortality in the elderly. American Journal of Epidemiology 163(10): 938-949.

Cutler DM, Glaeser EL, Shapiro JM. 2003. Why have Americans become more obese? Journal of Economic Perspectives 17(3): 93-118.

De Vriendt T, Moreno LA, DeHenauw S. 2009. Chronic stress and obesity in adolescents: scientific evidence and methodological issues for epidemiological research. Nutrition, Metabolism, and Cardiovascular Diseases: NMCD 19(7): 511-519.

Elia M. 2001. Obesity in the elderly. Obesity Research 9(4S): 244S-248S.

Engelhardt G. 2008. Social security and elderly homeownership. Journal of Urban Economics 63: $280-305$.

Engelhardt G, Gruber J, Perry C. 2005. Social security and elderly living arrangements: evidence from the social security notch. Journal of Human Resources 40: 354-372.

Finkelstein EA, Fiebelkorn IC, Wang G. 2003. National medical spending attributable to overweight and obesity: how much, and who's paying? Health Affairs. Web exclusive, W3-219.

Flegal KM, Carroll MD, Ogden CL, Johnson CL. 2002. Prevalence and trends in obesity among US adults, 1999-2000. Journal of the American Medical Association 288(14): 1723-1727.

Fujioka K. 2002. Management of obesity as a chronic disease: nonpharmacologic, pharmacologic, and surgical options. Obesity Research 10(Suppl 2): 116S-123S.

Garn SM, Leonard WR, Hawthorne VM. 1986. Three limitations of the body mass index. American Journal of Clinical Nutrition 44: 996-997.

Greve J. 2008. Obesity and labor market outcomes in Denmark. Economics and Human Biology 6(3): 350-362.

Gruber J, Frakes M. 2006. Does falling smoking lead to rising obesity? Journal of Health Economics 25: $183-197$.

Heckman J, Hotz J. 1989. Choosing among nonexperimental methods for estimating the impact of social programs: the case of manpower training. Journal of the American Statistical Association 84: 862-880.

Heiat A, Vaccarino V, Krumholz HM. 2001. An evidence-based assessment of federal guidelines for overweight and obesity as they apply to elderly persons. Archives of Internal Medicine 161: 1194-1203.

Heien D, Durham C. 1991. A test of the habit formation hypothesis using household data. Review of Economics and Statistics 73(2): 189-199.

Hill J, Wyatt HR, Reed GW, Peters JC. 2003. Obesity and the environment: where do we go from here? Science 299(7): 853-855.

Himes CL. 2000. Obesity, disease, and functional limitation in later life. Demography 37(1): $73-82$.

Iams HM, Ycas MA. 1988. Women, marriage and social security benefits. Social Security Bulletin 51(5): 3-9.

Kollmann G. 2003. Social Security Notch issue: a summary. Congressional Research Servie Report for Congress, Order Code 95-188 EPW. 
Krueger A, Pischke J-S. 1992. The effect of social security on labor supply: a cohort analysis of the notch generation. Journal of Labor Economics 10(4): 412-437.

Lakdawalla D, Philipson T. 2002. The growth of obesity and technological change: a theoretical and empirical examination. NBER Working Paper.

Lakdawalla D, Philipson T, Bhattacharya J. 2005a. Welfare-enhancing technological change and the growth of obesity. American Economic Review 95(2): 253-257.

Lakdawalla DN, Goldman DP, Shang B. 2005b. The health and cost consequences of obesity among the future elderly. Health Affairs 24: R30-R42.

Lundborg P, Bolin K, Hojgard S, Lindgren B. 2007. Obesity and occupational attainment among the 50+ of Europe. In The Economics of Obesity, Advances in Health Economics and Health Services Research, Kristian B, Cawley J (eds), vol. 17; 219-252.

Moran J, Simon K. 2006. Income and the use of prescription drugs by the elderly: evidence from the notch cohorts. Journal of Human Resources 41: 411-432.

Morris S. 2006. Body mass index and occupational attainment. Journal of Health Economics 25: 347-364.

Naik NY, Moore MJ. 1996. Habit formation and intertemporal substitution in individual food consumption. Review of Economics and Statistics 78(2): 321-328.

National Institutes of Health. 1998. Clinical guidelines on the identification, evaluation, and treatment of overweight and obesity in adults. NIH Publication 98-4083. NIH, Washington, DC.

Nieto-Garcia FJ, Bush TL, Keyl PM. 1990. Body mass definitions of obesity: sensitivity and specificity using selfreported weight and height. Epidemiology 1(2): 146-152.

Norton EC, Han E. 2008. Genetic information, obesity, and labor market outcomes. Health Economics 17(9): 1089-1104.

Philipson T. 2001. The world-wide growth in obesity: an economic research agenda. Health Economics 10: 1-7.

Philipson T, Posner RA. 1999. The long-run growth in obesity as a function of technological change. NBER Working Paper 7423.

Prentice AM, Jebb SA. 2001. Beyond body mass index. Obesity Reviews 2(3): 141-147.

Reno V, Ycas MA. 1982. Benefits for individual retired workers and couples now approaching retirement age. Social Security Bulletin 45(2): 25-31.

Rowland ML. 1989. Reporting bias in height and weight data. Statistical Bulletin 70(2): $2-11$.

Schmeiser MD. 2008. Expanding wallets and waistlines: the impact of family income on the BMI of women and men eligible for the earned income tax credit. Unpublished manuscript, Department of Consumer Science, University of Wisconsin at Madison.

Smalley KJ, Knerr AN, Kendrick ZV, Colliver JA, Owen OE. 1990. Reassessment of body mass indices. American Journal of Clinical Nutrition 52: 405-408.

Snyder SE, Evans W. 2006. The impact of income on mortality: evidence from the social security notch. Review of Economics and Statistics 88: 482-495.

Sobal J, Stunkard A. 1989. Socioeconomic status and obesity: review of the literature. Psychological Bulletin 105: 260-275.

Social Security Administration. 2006a. 'Social Security history'. World wide web content, http://www.ssa.gov/ history/notchfile1.html (Accessed December 21, 2006).

Social Security Administration. 2006b. 'Performance and accountability report for fiscal year 2006'. Available from: http://www.ssa.gov/finance/2006/Overview.pdf.

Stevens J, Cai J, Pamuk ER et al. 1998. The effect of age on the association between body mass index and mortality. New England Journal of Medicine 338(1): 1-7.

Stock JH, Wright JH, Yogo M. 2002. A survey of weak instruments and weak identification in generalized method of moments. Journal of Business and Economic Statistics 20(4): 518-529.

Swinburn BA, Caterson I, Seidell JC, Dietz WH, James WPT. 2002. The Scientific Basis For Diet, Nutrition, and the Prevention of Excess Weight Gain and Obesity. Background paper for Joint WHO/FAO Expert Consultation on Diet, Nutrition, and the Prevention of Chronic Disease.

US Department of Health and Human Services. 2001. The Surgeon General's Call to Action to Prevent and Decrease Overweight and Obesity. US Government Printing Office: Washington, DC.

World Health Organization (WHO). 2003. Diet, Nutrition, and the Prevention of Chronic Diseases. Report of a joint WHO/FAO Expert Consultation. 